\section{FÅ STUDENTER STRYKER I PRAKSIS}

\section{Store variasjoner. En nasjonal oversikt over stryk-} prosenten i praksis kan gjøre det lettere å kvalitetssikre praksisstudiene.
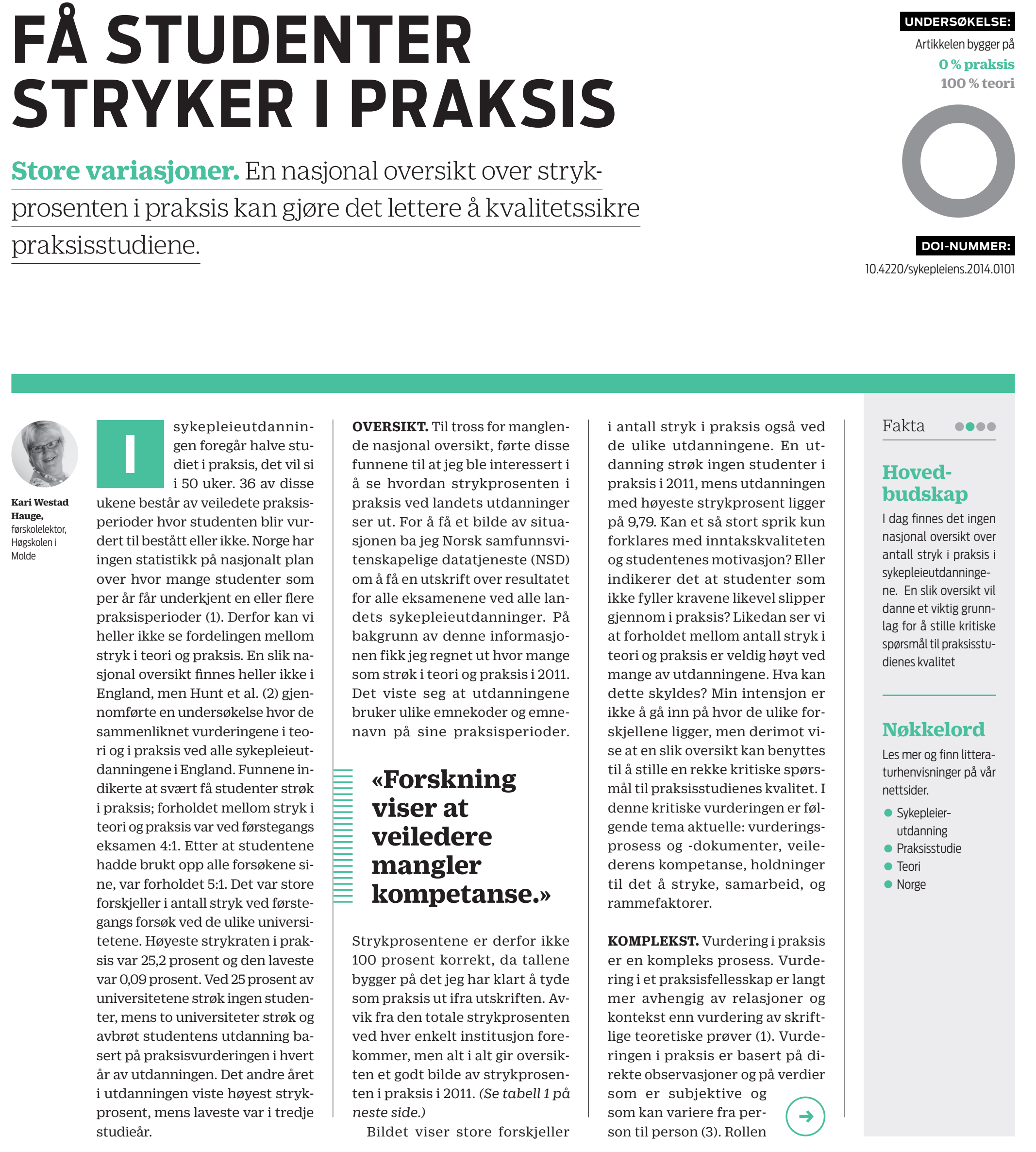

i antall stryk i praksis også ved de ulike utdanningene. En utdanning strøk ingen studenter i
praksis i 2011, mens utdanningen med høyeste strykprosent ligger på 9,79. Kan et så stort sprik kun forklares med inntakskvaliteten
og studentenes motivasjon? Eller indikerer det at studenter som ikke fyller kravene likevel slipper gjennom i praksis? Likedan ser vi at forholdet mellom antall stryk $\mathrm{i}$ teori og praksis er veldig høyt ved dette skyldes? Min intensjon er ikke å gå inn på hvor de ulike forskjellene ligger, men derimot vise at en slik oversikt kan benyttes tia denne kritiske vurderingen er føl. gende tema aktuelle: vurderingsprosess og -dokumenter, veilederens kompetanse, holdninger til det å stryke, samarbeid, og
rammefaktorer.

KOMPLEKST. Vurdering i praksis er en kompleks prosess. Vurdering iet praksisfellesskap er langt mer avhengig av relasjoner og ringen i praksis er basert på direkte observasjoner og på verdier som er subjektive og som kan variere fra perkontekst enn vurdering av skrift-

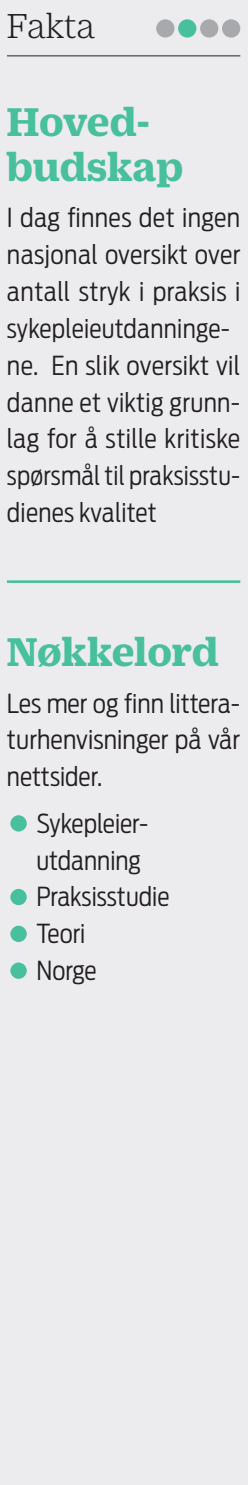

Fakta

Hovedoleieutdanninge-

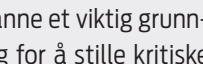

Tøkkkelord Les mer og finn litterarettside

- Sykepleier-
utdanning
- Praksistudie - Teori

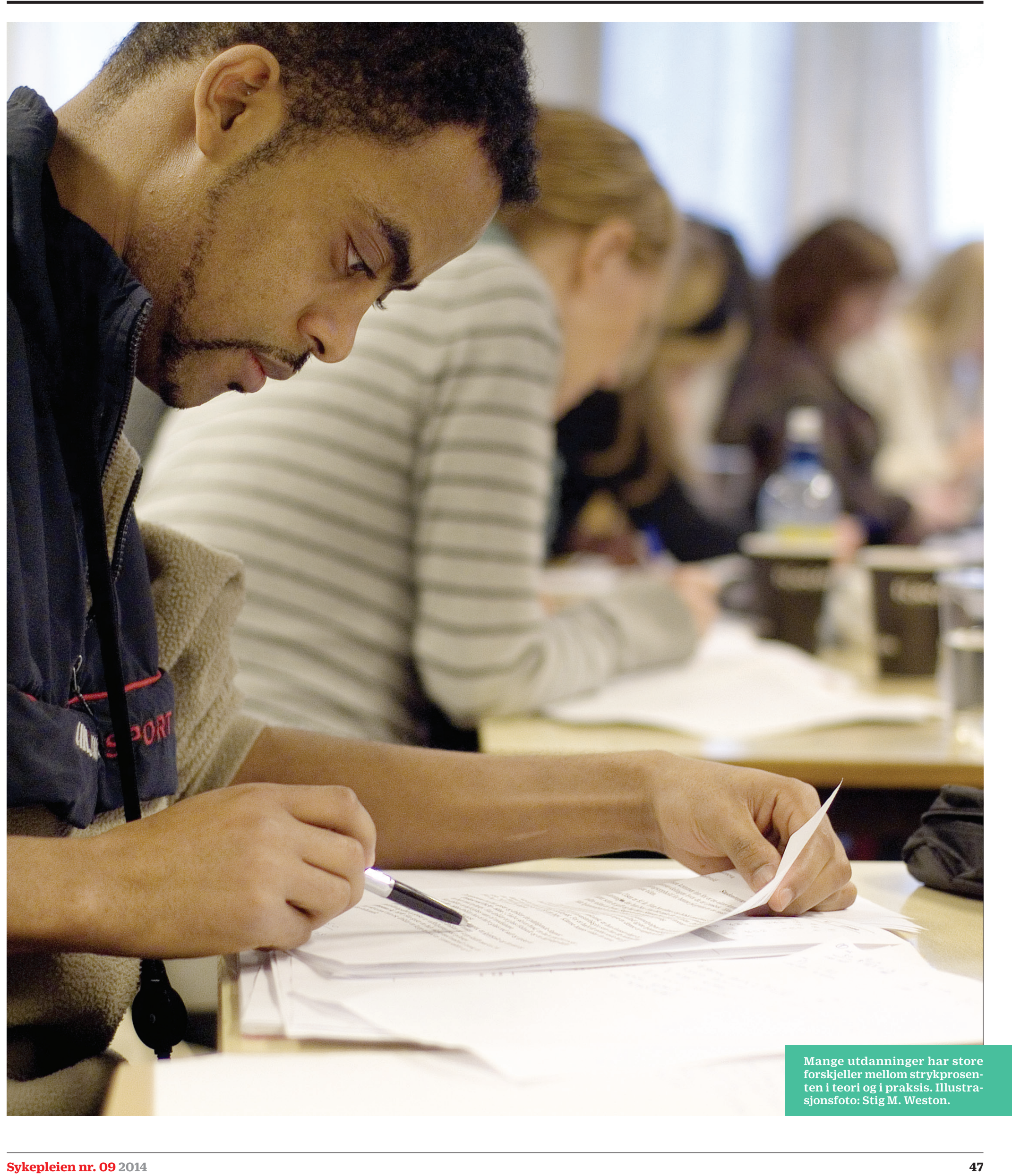


$\rightarrow \quad \begin{aligned} & \text { som veileder er utfordrendei det } \\ & \text { veileder skal balansere vurde- }\end{aligned}$ ringsprosessen med de daglige oppgavene og omsorg for pasientene (1). Å komme fram til avgjørelsen om ikke bestatt praksis for sonlige og ressursmessige utfordringer, noe som kan fore til at studenten består under tvil selv om det motsatte er mer forsvarlig (1). Forskning viser at inkompeente sykepleiestudenter får pa-

Prmuleringene ilæringsutbyttene som uklare og lite oppdaterte,

Tabell1. Strykprosent ved hoyskolene i 2011

\begin{tabular}{|c|c|c|}
\hline Utdanning & Strykprosent p praksis & Strykprosenti teori \\
\hline Betanien diakonale høgskole & 1,2 & 2,30 \\
\hline Diakonhjemmet diakonale høgskole & 1,1 & 8,60 \\
\hline Haraldsplass diaknanale høgskole & 0,0 & 4,50 \\
\hline Høgskolen i Akershus & 1,0 & 12,80 \\
\hline Høgskolen i Bergen & 1.53 & 4,85 \\
\hline Høgskolen i Buskerud & 3,01 & 12,34 \\
\hline Høgskolen i Finnmark & 1,62 & 15,55 \\
\hline Høgskolen i Giøvik & 1,66 & 15,31 \\
\hline Høgskolen i Harstad & 4,70 & 21,96 \\
\hline Høgskolen i Hedmark & 3,14 & 14,91 \\
\hline Høgskolen i Molde & 0,57 & 11,95 \\
\hline Høgskolen i Narvik & 1,83 & 22,95 \\
\hline Høgskolen i Nesna & 0,66 & 18.02 \\
\hline Høgskolen i Nord-Trøndelag & 1,10 & 13,44 \\
\hline Høgskolen Oslo & 2,45 & 17,37 \\
\hline Høgskolen i Sogn og Fijordane & 2,50 & 9,59 \\
\hline Høgskolen i Sør-Trøndelag & 0,26 & 13,57 \\
\hline Høgskolen i Telemark & 2,02 & 5,50 \\
\hline Høgskolen i Vestfold & 0,68 & 21,35 \\
\hline Høgskolen iØstfold & 0,90 & 14,30 \\
\hline Høgskolen i Allesund & 1,43 & 8,70 \\
\hline Høgskolen Stord/Haugesund & 2,28 & 15,64 \\
\hline Høgskolen Diakonova & 0,40 & 8,50 \\
\hline Lovisenberg diakonale høgskole & 0,90 & 9,55 \\
\hline Universititetet iAgder & 0,68 & 11,44 \\
\hline
\end{tabular}

Sentrale spørsmål her er om læklare som mulig for dem som skal ner ikke terminologien som blir fordi disse blir laget i utdanningrunn av manglende dokumentasjon (8.1213). Andre synes det er vanskelig å vurdere holdninger 9.). Kriterier for å vurdere holdfor sin bekymring muntlig (6). An dre igjen er ikke fortrolige med konkludere sine vurderinger (12) får økt kunnskap, men også gjenom ulike undervisningsmetoder og arbeidskrav får utviklet sin perhet med veilederrollen. Det er vi dere en utfordring for den enkelte utdanning og for profesjonen natrengs for å ta imot studenter er veldig stort.

Pedersen (1) hevder at å stryke en student i praksis medføre store ressursmessige og personligerelsen I en studie om vailederes erfaring med å gi i ikke beståt praksis, var det bred enighet om at det ville vært enklere for veileder å lukke øynene (16). Dette kan yde på at for à gi ikke bestått, $m$ a og ha et genuint engasjement for sykepleiefaget (1).

VEILEDERS HOLDNINGER. Studier viser at veiledere lar tvilen komme studenten til gode ford mens andre argumenter med at det for sent i utdanningen $(6,8,9)$. Motviljen mot å stryke en student sent iutdanningen bunner iat vei lederne tar hensyn til pengene (anden studentens framtid. Flere studier viser at det er vanskeligere å stryke en student man liker $(8-10,12)$ andre oppgir at det å stryke en sorg 68.8 . Studier viser a vise onledere ikke føler seg trygge på à stryke en student før han eller hun setter pasientens livi fare $(4,6)$. Holdninger til det å stryke kan være individuelle, men de kan os dersen (1) dersøkelse hvor hun innhentet opplysninger fra 30 enhetsledere. Noen avdelinger ga ikke bestâttt i praksis mer eller mindreår ig, ved andre avdelinger skjedde dere hadde i lopet av henholdsvis olv og femten år aldri opplevde at en student hadde fast tikke beslătt I praksis. En leder uttrykte: «Vi stry alltid å få dem giennom!r (1:134). E ter, blant annet som en frykt for bli stemplet som en «dårlig veileer» eller som en avdeling med dârlig læringsmiljø». Studier vi rist ern (8-10). Veiledere (9) frykter t slikt stempel skal medføre negav kritikk fra studenter og utdaningen. Veileder kan føle det som et personlig nederlag å stryke e som skyld os skam til detå stryte en student (6,8). Skjevheter i antal stryk i praksis mellom ulike praksissteder kan bunne i felles holdninger til det ã stryke i arbeidsfelesskapet. Det kan ogsá bunne

SAMARBEID. Veileder må ikk oppleve å stå alene i vurderingen av en svak student $(17,14)$. Betydningen av støtte fra kolleger er $(6,7,10,18)$. Brown et al. $(10)$ er (6,, 1,18$)$. Bdown et al. (10)
spurte isin studie nar informan tene ville søke støtte fra lærer. D storste svargruppene viste at 25 prosent ville tatt kontakt ide ta opp problemet og 75 prosent rett før eller umiddelbart ette

«Veiledning

og vurdering

av en svak

student er

tidkrevende."

midtvurdering. Her vil et sentralt spørsmål være hvordan samardanning. Er lærere tydelige på at veiledere skal slippe å stå alene en slik situasjon? Viser de gjendig stande vat de vilg nodvenat de får vite om at det trengs? Dette fordrer et tett samarbeid mellom praksis og utdanningen på personnivå, men også som samordnet lovverk og samaridsavtaler mellom utdanningsPedersen (1) og Aigeltinger m.fl. (14) hevder at veilederens arbeidstorhold ike er tistrekkevurderingen. Å være unnlatende lå stryke en inkompetent student kan skyldes mangel på tid (7,8). Personalknapphet fører til tign à observere studenten og bruke eller henne. Veiledning og vurkombineres med eilederens normale arbeidsopptodelte. Knapphet pa tid og den drende å folge opp en student. hår studenten er svak. Veiledere med stor arbeidsbyrde som føler giørelse som går i studentens favor (6). Disse utfordringene gjør man må diskutere om det skal stillingene.

KONKLUSJON. Kvalitetssikring praksisstudier krever vektleg. ging av og kritisk vurdering på eg trukket fram her. En nasjonal oversikt vil gjøre det mulig å se noenlunde stabil, om det forekommer variasjoner mellom læresteder og praksisavdelinger i landet. Tallene kan danne grunnlag for en kritisk vurdering av momentene som har størst betydpraksisstudiene. Målet er ikke at flest mulig studenter skal stryke i praksis, men at man har et system som i størst mulig grad sikrer studentene en god veiledningsog vurderingsprosess. På den måkompetente studenter består og at studenter urettmessig opplever å ikke bestå praksis.

En nasjonal oversikt krever

utdanningene bruker emnekode og emnenavn som dier, is sin rapportering til databasen for hoyere utdanning. Saken må derfor behandles på nasjo-

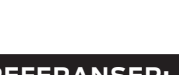

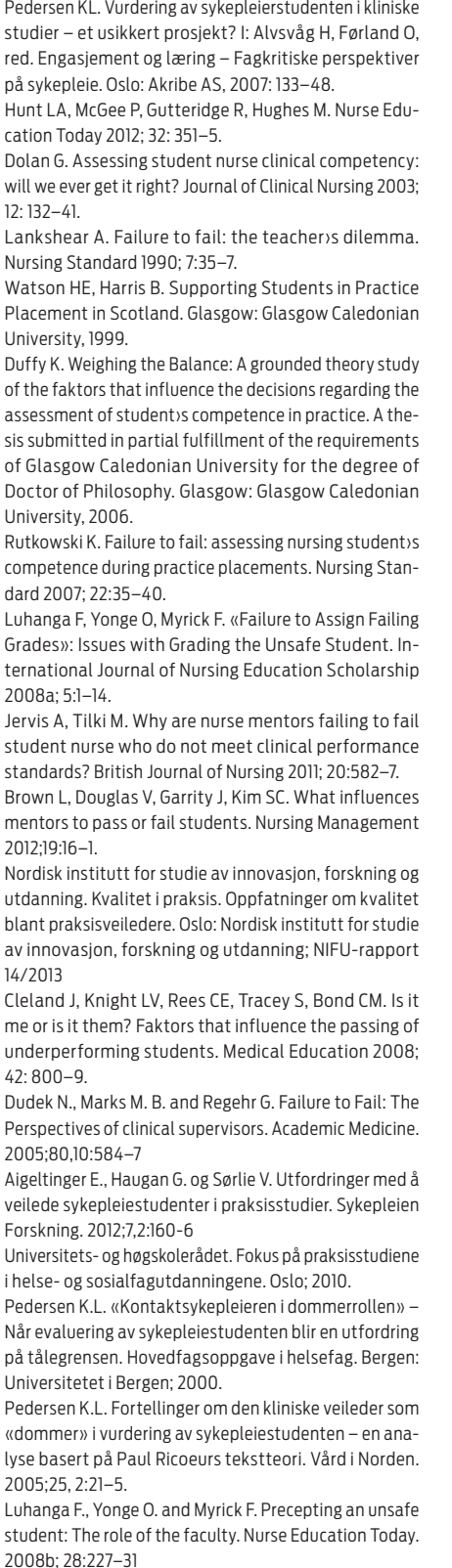

FAGARTIKLER:

Fagartiklerkan sendes til
torhild.apall@sykepleien.no 